\title{
Study on Socio-Economic Profile of Millet Consumers in Jodhpur District of Rajasthan and Chitradurga Districts of Karnataka, India
}

\author{
Bhagirath Das ${ }^{1 *}$, Satyapriya ${ }^{2}$ and Poulami Ray ${ }^{3}$
}

${ }^{1}$ Ph.D. Scholar, ${ }^{2}$ Principal Scientist; Division of Agricultural Extension, ICAR - Indian Agricultural Research Institute, New Delhi, India

${ }^{3}$ Ph.D. Scholar, Division of Dairy Economics, Statistics and Management, ICAR-National Dairy Research Institute, Karnal, Haryana, India

"Corresponding author: bhagirathdas5@gmail.com

Received: 04 Jan., 2020

Revised: 07 Apr., 2020

Accepted: 20 May, 2020

\begin{abstract}
Millets are highly nutritious food and are widely cultivated in India since long. But from last few decades land under cultivation of millets is decreasing due to decrease in demand. Owning to its nutritional and health benefits the demands of millets are now increasing among urban consumers. To understand the socio-economic profile of millet consumers a study was undertaken in Jodhpur district of Rajasthan and Chitradurga district of Karnataka. It was found that most of the urban families were nuclear families, in contrast, most of the rural families were joint families. Most of the millet rural consumers in Jodhpur were medium and semi-medium farmers, whereas in Chitradurga most of the farmers were small and marginal farmers. In terms of educational qualification,most of the rural consumers in both the districts (32.5 per cent) had completed primary level of education and most of the consumers in urban areas (45 per cent) had completed secondary level of education.
\end{abstract}

Keywords: Millet, Nutrition, Consumer, Rural, Urban

Millets which are also known as 'coarse cereals' require less inputs, are more resistant to biotic and abiotic stress. Millets play an important role in the cropping pattern of dryland agriculture. Millets are mostly grown as dual-purpose crops to meet both food and fodder requirements. For centuries millets have been an important part of traditional diet of millions of people in India. However, from last few decades, there has been a sharp decrease in area of cultivation of millets due to decline in demand as a result of changing food habit (Reddy et al. 2013), availability of cereals i.e., rice and wheat through PDS (Public Distribution System) at cheaper price and millets loosing area to commercial crops due to improved access to inputs required by the commercial crops. Millets are considered as 'nutricereals' considering their nutritional importance and they are now gaining more consumer acceptance especially among urban consumers. The study of socio-economic profile is basis of social research (Panda, So, a study was undertaken to understand

How to cite this article: Das, B., Satyapriya and Ray, P. (2020). Study on Socio-Economic Profile of Millet Consumers in Jodhpur District of Rajasthan and Chitradurga Districts of Karnataka, India. International Journal of Inclusive Development, 6(1): 07-10.

Source of Support: None; Conflict of Interest: None 
the socio-economic status of the rural and urban consumers of millets.

\section{MATERIALS AND METHODS}

For the present study, Rajasthan and Karnataka were selected purposively as these two states rank first in both areas of cultivation and production of pearl millet and finger millet in India. From each state, one district was selected (Jodhpur in Rajasthan and Chitradurga in Karnataka) purposively based on the area of production as well as administrative convenience; from each district one block and from each block two villages were selected randomly. From each village, thirty rural consumers were selected by simple random sampling technique; so, the total sample size was one hundred and twenty. Sixty urban consumers (30 from each district) were also randomly selected to collect data thus making the total sample size 180. It is to be noted that the rural consumers selected were also farmers who were growing millets.

Table 1: Distribution of respondents $(n=180)$

\begin{tabular}{cccc}
\hline Districts & Rural consumers & Urban consumers & Total \\
\hline Jodhpur & 60 & 30 & 90 \\
Chitradurga & 60 & 30 & 90 \\
\hline Total & $\mathbf{1 2 0}$ & $\mathbf{6 0}$ & $\mathbf{1 8 0}$ \\
\hline
\end{tabular}

\section{Selection of the variables and their measurement}

Age: It was measured as the chronological age of the respondents during the time of investigation. The respondents were classified into three categories viz. young ( 35 years and below), middle-aged (36-59 years) and old (60 years and above).

Education: It referred to the respondents' academic qualification acquired through formal schooling measured in years. Respondents were categorized into six categories viz. illiterate, functionally literate, primary, high school, graduate and postgraduate according to their level of education.

Family type: It was measured in terms of cooking arrangements and pooling of income. The families that had pooled all their income and had common cooking arrangement despite the presence of more than a couple were considered joint family and otherwise, nuclear.
Caste: It refers to a social category, whose members are assigned a permanent status by birth within a given social hierarchy. It was measured by directly asking. Respondents were categorized into four groups viz., general, other backward caste, schedule caste and schedule tribe.

Farming Experience: It was operationalized as the number of years one was engaged in farming activities. It was measured by taking the actual data on chronological years of involvement in farming.

Land holding: It was operationalized by taking up the total size of land owned and cultivated the respondents. For the classification of respondents, the criterion adopted by the Ministry of Rural Development Circular, Government of India (1992) was used. Respondents were categorized into five groups viz. marginal ( $<1 \mathrm{ha})$, small (1-2 ha), semimedium (2-4 ha), medium (4-10 ha) and large (> 10 ha).

\section{RESULTS AND DISCUSSION}

\section{Socioeconomic Status of Consumers}

The socioeconomic approach is mainly concerned with the social, economic, and political aspects of individuals or social groups in society (Adger, 1999). Generally, the socioeconomic approach focuses on identifying their internal characteristics such as, education, gender, wealth, health status, access to credit, access to information and technology, formal and informal (social) capital, political power, and so on. The findings about the socioeconomic status of the study area are given below.

Age

Table 2: Age Distribution of Consumers

\begin{tabular}{cccccc}
\hline \multirow{2}{*}{ Parameter } & \multirow{2}{*}{ Classification } & \multicolumn{2}{c}{ Rural } & \multicolumn{2}{c}{ Urban } \\
\cline { 3 - 6 } & & $f(\%)$ & Mean & $f(\%)$ & Mean \\
\hline \multirow{2}{*}{ Age } & Young $(<35$ & 7 & & $8(13.33)$ & \\
& Years $)$ & $(5.83)$ & 49.84 & & 44.69 \\
& Middle $(35-59$ & 85 & & 43 & \\
& Years $)$ & $(70.83)$ & $(71.67)$ & \\
& & 28 & & & \\
& Old (> 59 Years) & $(23.33)$ & & & \\
& & & &
\end{tabular}

Figures in parentheses denote Percentage.

Table 2 describes the age distribution of rural and urban consumers. The average age of 120 rural 
consumers in both the districts was found to be 49.84 years and most of them $(70.83 \%)$ were middle aged. On the other hand, the average age of 60 urban consumers in both the districts was 44.69 years and 71.67 per cent of them were middle aged. In total,a smaller number of respondents belonged to young age category which is 5.83 per cent of rural consumers and 13.33 per cent of urban consumers.

\section{Caste}

It is evident from table 3 that out of total 120 rural consumers and 60 urban consumers in both the districts, 59.16 per cent rural consumers and 45 per cent urban consumers belonged to Other Backward Caste $(\mathrm{OBC})$ category and were predominant caste in the study area. On the other hand, Schedule Tribe (ST) category of people comprised only 1.67 per cent of the rural consumers and 8.33 per cent of the urban consumers out of the two districts.

Table 3: Distribution of Consumers according to Caste

\begin{tabular}{cccc}
\hline \multirow{2}{*}{ Parameter } & Classification & Rural & Urban \\
\cline { 3 - 4 } & & $f(\%)$ & $f(\%)$ \\
\hline \multirow{3}{*}{ Caste } & General & $28(23.33)$ & $20(33.33)$ \\
& OBC & $71(59.16)$ & $27(45.00)$ \\
& SC & $19(15.83)$ & $8(13.33)$ \\
& ST & $2(1.67)$ & $5(8.33)$ \\
\hline
\end{tabular}

Figures in parentheses denote Percentage.

\section{Family type}

In rural areas, of total rural consumer families in both the districts, 53.34 per cent were joint families. But in urban areas out of total urban consumer families 70 per cent were nuclear families which is in sharp contrast to what was observed in rural areas.

Table 4: Distribution of Consumers according to Family type

\begin{tabular}{lccc}
\hline \multirow{2}{*}{ Parameter } & \multirow{2}{*}{ Classification } & Rural & Urban \\
\cline { 3 - 4 } & & $f(\%)$ & $f(\%)$ \\
\hline \multirow{2}{*}{ Family type } & Nuclear Family & $56(46.67)$ & $42(70.00)$ \\
& Joint Family & $64(53.34)$ & $18(30.00)$ \\
\hline
\end{tabular}

Figures in parentheses denote Percentage.

\section{Education}

Out of total rural consumers, most of the consumers i.e. 32.5 per cent had completed primary level of education and 28.33 per cent of them were illiterate. In urban areas, most of the consumers i.e. 45 per cent had completed secondary level of education whereas no one were reported to be illiterate.

Table 5: Distribution of Consumers according to level of Education

\begin{tabular}{lccc}
\hline \multirow{2}{*}{ Parameter } & Classification & Rural & Urban \\
\cline { 3 - 4 } & & $f(\%)$ & $f(\%)$ \\
\hline Education & Illiterate & $34(28.33)$ & $0(0.00)$ \\
& Functional literate & $11(9.17)$ & $0(0.00)$ \\
& Primary level & $39(32.5)$ & $9(15.00)$ \\
& Secondary level & $21(17.5)$ & $27(45.00)$ \\
& Graduate & $8(6.67)$ & $19(31.66)$ \\
& Post-graduate & $7(5.83)$ & $5(8.33)$ \\
\hline
\end{tabular}

Figures in parentheses denote Percentage.

\section{Land holding}

As all the rural consumers were farmers also, so farming related data was also collected from the respondents. It was observed, out of 60 farmers in Jodhpur, most of the farmers i.e. 45 per cent belonged to semi-medium category followed by medium category i.e. 26.66 per cent of farmers whereas there was no marginal category of farmers in the respondents' group. Contrast to this, in Chitradurga district out of 60 farmers most of them belonged to small (33.33 per cent) and marginal (30.00) category. In Jodhpur, 20 per cent of the farmer respondents belonged to large farmer category as compared to only 1.66 per cent farmer respondents in Chitradurga district. The average land holding of farmer respondents in Jodhpur district was higher (7.34 ha) as compared to Chitradurga (2.04 ha). So, it is evident that farmer respondents in Jodhpur possess higher land holding than in Chitradurga. However, it is to be noted that Jodhpur being an arid zone farmers had large chunk of land holding and most of the farmlands were not irrigated whereas in Chitradurga most of the farmlands were under irrigation facilities.

\section{Farming experience}

Out of the 60 farmers in Jodhpur, most of the farmer respondents ( 41.66 per cent) had more than 40 years of farming experience followed by farmers (40 per cent) who had 31-40 years of farming experience. While in Chitradurga most of the farmers (38.33 per cent) had 21-30 years of farming experience 
Table 6: Distribution of Consumers according to Land holding

\begin{tabular}{|c|c|c|c|c|c|}
\hline \multirow{2}{*}{ Parameter } & \multirow{2}{*}{ Classification } & \multicolumn{2}{|c|}{ Jodhpur } & \multicolumn{2}{|c|}{ Chitradurga } \\
\hline & & $f(\%)$ & Mean & $f(\%)$ & Mean \\
\hline \multirow{5}{*}{ Land holding } & Marginal (<1 ha) & $0(0)$ & & $18(30)$ & \\
\hline & Small (1-2 ha) & $5(8.33)$ & & $20(33.33)$ & 2.04 \\
\hline & Medium (2-4 ha) & $16(26.66)$ & 7.34 & $17(28.33)$ & \\
\hline & Semi-medium (4-10 ha) & $27(45.00)$ & & $4(6.66)$ & \\
\hline & Large (>10 ha) & $12(20.00)$ & & $1(1.66)$ & \\
\hline
\end{tabular}

Figures in parentheses denote Percentage.

followed by farmers (28.33 per cent) having more than 40 years of farming experience. In both the districts, very few of the farmers in respondents' group were young farmers and especially in case of Jodhpur district, there was no young farmer respondents who had farming experience below 10 years.

Table 7: Distribution of rural consumers according to their farming experience

\begin{tabular}{cccc}
\hline \multirow{2}{*}{ Parameter } & Classification & Jodhpur & Chitradurga \\
\cline { 3 - 4 } & & $f(\%)$ & $f(\%)$ \\
\hline \multirow{3}{*}{ Farming } & $1-10$ Years & $0(0)$ & $3(5.00)$ \\
experience & 21-20 Years & $2(3.33)$ & $2(3.33)$ \\
& 31-40 Year & $9(15.00)$ & $23(38.33)$ \\
& $>40$ Years & $24(40.00)$ & $15(25.00)$ \\
& $25(41.66)$ & $17(28.33)$ \\
\hline
\end{tabular}

Figures in parentheses denote Percentage.

\section{CONCLUSION}

The socioeconomic characteristics of farmer and farm are important for better policy options. Due to low profitability younger generation is not much interested in agriculture and are moving towards other sectors as it is evident from the socio-economic data and was also mentioned by the farmer respondents during the interaction. As indicated by various studies, here also it is found that most of the farmers are small holders and land holding is continuously shrinking due to fragmentation which makes agriculture challenging to make profitable venture. As a result farmers are inclining more towards input intensive agriculture, commercial and cash crop cultivation, etc.

\section{REFERENCES}

Adger, W.N. 1999. Social vulnerability to climate change and extremes in coastal Vietnam. World Development, 27(2): 249-269.

Panda, C.K. 2014. Information Sources and Technology Adoption by Farmers: An Empirical study in Mohanpur Block, West Tripura. International Journal of Extension Education, 10: 80-87.

Reddy, A.A., Yadav, O.P., Malik, D.P., Singh, I.P., Ardeshna, N.J., Kundu, K.K. and Reddy, K.S. 2013. Utilization Pattern, Demand and Supply of Pearl Millet Grain and Fodder in Western India. Working Paper Series No. 37. Patancheru 502 324, Andhra Pradesh, India: International Crops Research Institute for the Semi-Arid Tropics, pp. 24. 